\title{
Bauhaus-skolan en modell för Konstfackskolan 1944
}

Kerstin Wickman

Under åren som lektor från 1984 och som professor i design- och konsthantverkshistoria från 2002 till 2008 på Konstfack fördjupade jag mig ett antal gånger i Bauhausskolans respektive Konstfacks bakgrund, historia och utveckling. Jag höll bland annat en rad föreläsningar om Bauhaus och modernismen, ur olika aspekter. Bauhausskolans 100-årsjubileum 2019 innebar att jag som reseledare och föreläsare för några grupper med svenska formgivare besökte jubileumsutställningarna i Berlin, Weimar och Dessau.

Kvaliteten på den konstindustriella utbildningen i Sverige var ett problem under de första decennierna på 1900-talet, enligt kretsen kring Svenska Slöjdföreningen (sedan 1976 Svensk Form). Kritiken var återkommande.
Bauhausskolan hade uppfattats som en omtumlande innovation i Weimar 1919, vilken förändrat estetiken och pedagogiken på ett genomgripande sätt men som slutat $i$ en tragedi 1932-33. Konstfack har överlevt både kritik, upproriska studenter och en rad omdaningar och är nu 176 år. Den har sedan den blev högskola 1976-78 genomgått ytterligare förändringar. Här kommer jag ta upp några av beröringspunkterna med Bauhaus.

"Slöjdskolan" (nuvarande Konstfack) fick sitt nya namn "Tekniska skolan" och en ny utbildningsplan 1878-79. Det var en skola för slöjd, konsthantverk, formgivning och blivande teckningslärare. Här fanns även en byggnads- och maskinteknisk avdelning. Dess ursprung var Söndagsritskolan för hantverkare som grundats 1844. Ett år senare blev Svenska Slöjdföreningen huvudman och skolan kallades därefter allmänt för "Slöjdskolan". Staten tog över det ekonomiska ansvaret 1859, och som nämndes ovan fick skolan 1879 en ny, då modern utbildningsplan.

En viss modernisering skedde därefter kring sekelskiftet. Vid sidan av undervisningen i stilhistoria och ornament fick eleverna teckna direkt från naturen. Men sedan upphörde förnyelsen. På 1920- och 1930-talen klagade Svenska Slöjdföreningen på att undervisningen var otidsenlig. Upplägget, metodiken och pedagogiken hade inte väsentligt förändrats sedan 1879. Skolan hade lunkat på med i stort sett samma pedagogiska upplägg.

Stockholmsutställningen 1930 blev ett genombrott för funktionalismen (modernismen) i Sverige för arkitektur, konstindustri och formgivning. Men Tekniska skolan var inte representerad på utställningen, med undantag för de elever som studerade för monumentalmålaren och kyrkomålaren Olle 


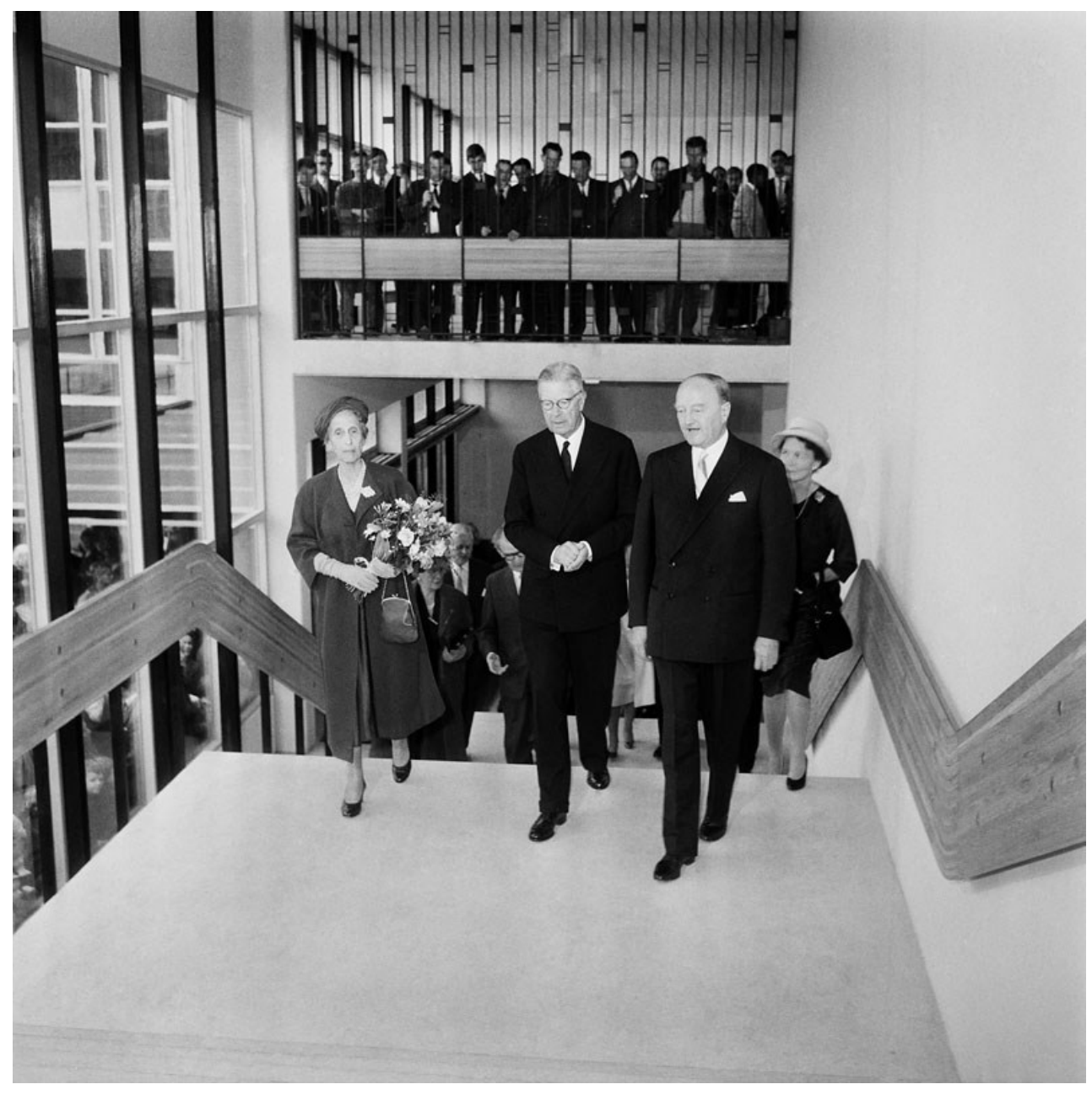

Bild 1. Konstfacks byggnad idag på LM Ericssons väg i Stockholm. Skolan fick i början av 2000-talet, liksom Bauhaus-skolan 1932, flytta in i f. d. telefonfabrik. L.M. Ericssons telefonfabrik uppfördes 1938 till 1940 i funktionalistisk stil efter ritningar av arkitekt Ture Wennerholm. Foto: Ivar Johansson. CC.
Hjortzberg (1872-1959). Hans undervisning ansågs nämligen vara den enda som svarade mot moderna behov. Hans elever fick måla teaterscenografier och en del paviljonger på utställningen. En av eleverna var prins Sigvard Bernadotte (1907-2002), som senare blev en av Sveriges första industridesigner.

\section{Krav på förnyelse}

Efter Stockholmsutställningen började det emellertid ta fart. Utställningens energiske kommissarie, konsthistorikern Gregor Paulsson (1889-1977), Svenska Slöjdföreningens direktör, museimannen Erik Wettergren (1883-1961) och föreningsmedlemmen, arkitekten Hakon Ahlberg (1891-1984) utformade en skrivelse till skolöverstyrelsen med synpunkter på hur en modern utbildning $\mathrm{i}$ formgivning och konstindustri borde se ut. Skrivelsen publicerades i Form, Svenska Slöjdföreningens tidning. ${ }^{1}$ Här några rader ur texten: "Skolan är i behov av en radikal omorganisation. Den moderna konstindustrin fordrar sålunda långt mer ingående tekniska kunskaper och en djupare insikt om industriens arbetssätt och ekonomiska förhållanden. Den hämtar sina former icke ur 


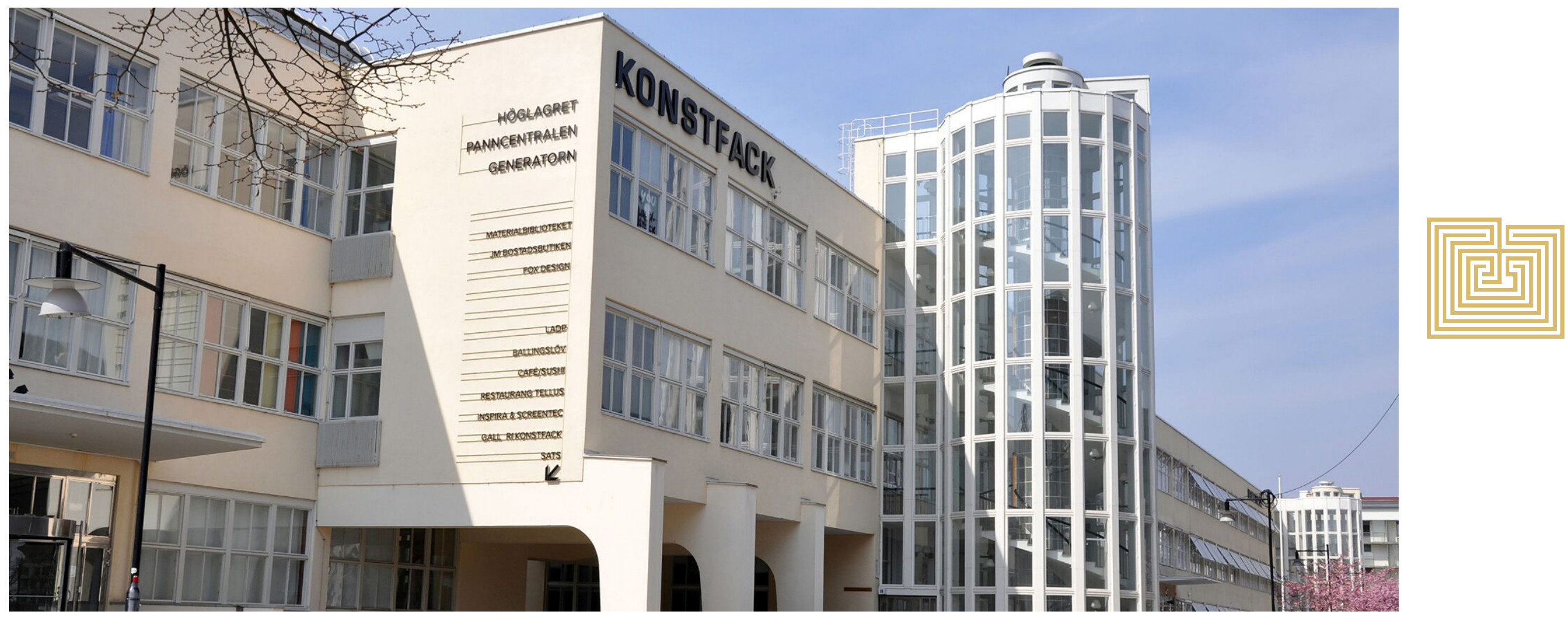

Bild 2. De nya lokalerna av Konstfackskolan på Valhallavägen i Stockholm invigs i November 1959 av kung Gustaf VI Adolf och drottning Louise. Foto: Jan Ehnemark, Stockholms stadsmuseum, Fotonummer: SvD 27567. 
ett förråd av ornament i olika stilarter eller av tillfällig karaktär utan den söker att nå fram till konstnärlig verkan i främst rummet genom ett inträngande studium av materialets inneboende möjligheter i dess samverkan med konstruktion och ändamål."2

Åsikten att det var materialen i sig som skulle vara utgångspunkten delade de tre förslagsställarna med lärarna och ledningen för Bauhaus-skolan, samt även med många dåtida avantgardekonstnärer. Det var en av de stora förändringarna jämfört med 1800-talet och sekelskiftet, då stilhistorien respektive återgivningen av naturen varit i fokus.

Förslagsställarna hade fler krav: "Stor uppmärksamhet bör ägnas åt metodiken vid denna konstnärliga fackutbildning och därvid böra erfarenheter från utlandets ledande konstindustriskolor studeras. Skolan måste sålunda utrustas med verkstäder eller laboratorier för respektive fack och det är önskvärt att dessa i möjligaste mån förses med de tekniska hjälpmedel av vilka industri och hantverk i praktiken begagna sig. [---] Skolans facklärare böra även själva om möjligt hava direkt kontakt med industri och hantverk. Skolan böra i viss mån kunna tjänstgöra såsom modell- och mönsterverkstad för resp. industrier, och eleverna böra sålunda i den utsträckning det är möjligt sysselsättas med direkta beställningar från industrien eller med att framställa säljbara mönster."3

Det som föreslås liknar alltså inte endast programmet för Bauhaus-skolan. Förslagen är näst intill identiska med Walter Gropius utbildningsplaner, som handlade om att utveckla nya prototyper för tysk industri.

\section{Tyskland - inte längre en förebild}

Men det politiska händelseförloppet i Tyskland på 1930-talet var ett problem. Tyskland var inte längre ett exempel att följa. I Form år 1933 tog Gregor Paulsson avstånd från utvecklingen i det land vars kultur hade betytt så mycket för honom.

Både kulturen och pedagogiken tog en annan väg efter 1932, efter nazisternas maktövertagande. I Form publicerades 1933 en lista på ett tjugotal museichefer och professorer som då tvingades lämna sina arbeten, bl. a. den kände förkämpen för den moderna typografin, Jan Tschichold (1902-1974), lärare i grafisk formgivning i Leipzig. Även chefredaktören för den tyska tidskriften $D e r$ Form entledigades. Dess svenska motsvarighet, Form, konstaterade att Walter Gropi- us och Ludwig Mies van det Rohe hade gått ur Deutscher Werkbund, som nu fått en partitrogen, nationalsocialistisk ledning. ${ }^{4}$

Men vad innebar det för konsthantverksskolorna? Skribenten Hans Rabén ${ }^{5}$ rapporterade i Form om en resa till Hamburg och skriver: "Syftet med besöket var att se hur den nazistiska pedagogiken fungerade i praktiken på en konstindustriskola." Hans artikel har rubriken "En tysk konstindustriskola under den nya regimen". ${ }^{6}$ Rabén är ömsom kritisk och ömsom ironisk i sin artikel. Den kände, tidigare rektorn för skolan hade sparkats. Orsaken var hans förkärlek för modern konst och för de idéer som tillämpats på den forna Bauhaus-skolan i Dessau. Rabén påpekade i sin artikel att de nu förbjudna idéerna var desamma som de vilka i Sverige kalllades funktionalism. Några nya pedagogiska linjer erbjöd inte den nazistiska omställningen, konstaterade han.

Man hade återgått till att teckna av naturen och gamla gipsmodeller, "i stället för att utgå från materialet som varit Bauhausskolans modell". Periodvis fick eleverna ägna sig åt "lantbruksarbete enligt den nazistiska Blut und Boden-ideologin". I arkitekturutbildningen fick de lära sig "att taket ska inta två tred- 
jedelar av hushöjden och utformas i samma anda som den nordtyska allmogekulturen". På textilavdelningen ägnade man sig inte åt färgning av garn. "Växtfärgning saknas nästan helt, vilket kan tyckas egendomligt med den kult av det jordvuxna som nu bedrives $\mathrm{i}$ Tyskland", ironiserade han. ${ }^{7}$

\section{Omdaningen tog form}

Skrivelsen ledde till att skolöverstyrelsen tillsatte en kommitté med yrkessakkunniga 1936 som skulle ta fram en ny utbildningsplan och ett förslag på omorganisation. Förslaget var klart två år senare men det dröjde till 1945 innan det blev officiellt beslutat av regering och riksdag.

Undervisningen på Konstfack var fram till 1978 - då skolan blev högskola -indelad i en lägre och högre avdelning, den tvååriga Dagskolan och den tvååriga Högre Konstindustriella Skolan, HKS. Till den sistnämnda antogs man genom inträdesprov. Åren 1968-70 ändrades detta och godkända elever kunde automatiskt fortsätta till HKS. Det fanns även en treårig Aftonskola för elever som yrkesarbetade dagtid. Utbildningen där motsvarade den tvååriga Dagskolan. Många av dem som togs in på Dagskolan hade först gått ett till tre år på Aftonskolan, som emellertid upphörde 1978 när Konstfack blev högskola.

Aftonskolan och Dagskolan gav eleverna en gemensam konstnärlig bas och möjlighet att fundera över vilket fack de därefter eventuellt ville gå. Jämfört med Bauhaus tog eleverna på Konstfack längre tid på sig för att ta en examen. Men de var betydligt yngre än dem som kom till Bauhaus-skolan i Weimar och hade inte lika grundliga konststudier bakom sig.

Konstfacks nya namn visade att utbildningen nu byggde på fack. Dessa leddes dels av huvudlärare som ansvarade för elevernas konstnärliga och professionella utveckling, dels av hantverkare som undervisade i olika tekniker. Modellen var alltså densamma som på Bauhaus. Dessutom fanns en rad andra lärare som bidrog till elevernas kunskaper om färg, form och ljus, precis som det funnits på Bauhaus. Bauhaus-skolan var alltså en förebild.

Men det fanns också en skillnad. För Walter Gropius, som den arkitekt han var, var "byggnaden" målet. Flera arkitekter knöts ju också till Bauhaus som lärare. Svenska Slöjdföreningens målgrupp, liksom sakkun- niggruppens, var landets konstindustrier, något som kom att prägla utbildningen. Målet var att få fram fler skickliga formgivare som kunde bistå den svenska industrin. (Den byggnads- och maskintekniska avdelningen hade redan avknoppats 1938 från Tekniska skolan, och blivit ett nytt tekniskt läroverk i Stockholm.)

År 1946 utsågs konsthistorikern Åke Stavenow (1898-1971) till rektor för Konstfack. Han kom från Svenska Slöjdföreningen, för vilken han varit direktör. Han hade också ingått i den kommitté som utformat den nya utbildningsplanen. Hans uppdrag var att förnya skolan enligt de riktlinjer som föreslagits i debattartikeln 1933 och i den omdaning som riksdagen beslutat 1945 . Den akademiskt eller hantverksmässigt utbildade lärarkåren som funnits på Tekniska skolan var inte alltid med på noterna. (Detsamma hade Gropius upplevt i Weimar.) De fanns dock undantag, bl.a. konstnären Nils Nixon (1912-1998), som fördjupat sig i László Moholy Nagys pedagogiska övningar på New Bauhaus i Chicago. Nixon arbetade som lärare i konstpsykologi på skolan, ett ämne som också omfattade perceptionsövningar. I och med att nya huvudlärare anställdes 
upphörde motståndet mot förändringarna. Stavenow rekryterade några av dåtidens främsta yrkesverksamma formgivare och konstnärer i Sverige.

Flera av lärarna på Konstfackskolan arbetade $i$ ett abstrakt formspråk och direkt med materialen, dvs. med yttringar som på 1920-talet betraktats som avantgarde, men som blev rådande efter andra världskriget. Att utgå från och fördjupa sig i materialen och färgerna, att förutsättningslöst närma sig problemen och att ha ett experimentellt förhållningssätt till skapande var de pedagogiska idéer som Konstfackskolan kom att omfatta efter kriget, precis som Bauhausskolan gjort före kriget.

\section{Fack baserade på material}

På keramik- och metallfacken ingick industriella formgivningsuppgifter, medan textilfacket var fokuserat på textil konst och hantverk. Ett fåtal textilkonstnärer sadlade efter examen om till mönsterformgivare på textilindustrin eller sökte till NK:s (Nordiska Kompaniets) Textilkammare, där Astrid Sampe (1909-2002) var chef. Hon hade börjat på Tekniska skolan (Konstfack) 1928 och sedan studerat på Royal College of Art i London.
Där lärde hon känna den tidiga brittiska modernistgenerationen. Precis som Bauhauslern Otti Berger (1898-1944), som under en period ansvarade för undervisningen i vävning på Bauhaus i Dessau, var Astrid Sampe oerhört intresserad av industriella textiltekniker och nya fibrer som cellulosa, cellofan, viskos, rayon och glasfiber.

Otti Berger hade kommit till Sverige i april 1929 för att följa en kurs på Johanna Brunssons vävskola, den så kallade Praktiska vävnadsskolan, under elva veckor. Kursen avslutades med en växtfärgningsperiod med Barbro Nilsson som lärare. (Nilsson blev senare huvudlärare för textilavdelningen på Konstfackskolan.) I januari 1930 visade Otti Berger sina textilier på Galerie Moderne i Stockholm samtidigt som en utställning med "radikal" modernistisk svensk bostadsarkitektur - liknande den tyska - presenterades. Hon fick en kort, uppskattande recension i Dagens Nyheter. Form publicerade en artikel och i tidningen Spektrum, Arkitektur och samhälle, nr 2, 1933, ingick hennes intressanta och analytiskt skärpta artikel "Rätt fibrer på rätt plats". I den beskriver hon vilka funktioner textilier ska ha i inredningen och hur strukturer och färger påverkas av material och ljus.
Sådana kunskaper anammades av Astrid Sampe. Genom Otti Bergers vistelse och hennes föreläsningar i Stockholm 1929 spreds Moholy-Nagys betoning på olika materials unika och taktila egenskaper till svenska formgivare. Enligt modernister som Sampe och studenterna på Konstfackskolan, skulle textilierna samspela med den nya moderna funktionalistiska betongarkitekturen. Inga små, räddhågsna mönster dög i fönstren. Det skulle vara storskaliga, abstrakt mönstrade eller enfärgade textilier, som fångade dagsljuset och hämmade skarpa ljud, slitstarka möbeltyger, som framhävde möblernas formspråk och stora textila konstvävar, som bidrog till intressanta interiörer.

\section{Vad hände sedan}

I samband med 150-årsjubileet 1993 bytte Konstfackskolan officiellt namn till Konstfack, som skolan då inofficiellt hade kallats under fler decennier. Jubileet firades bl. a. genom att en stor jubileumsbok gavs ut. Konstnären Gösta Wessel (f. 1944), professor vid skolans avdelning för Färg och Form var en av skribenterna.

I och med att Konstfack blev högskola 1978 fick skolan då en speciell avdelning,

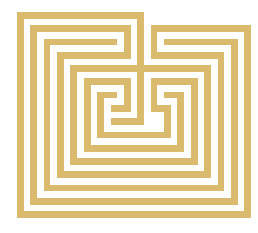


"Färg och Form", som stod för en tredjedel av all undervisning på skolan och som skulle säkerställa att eleverna fick den konstnärliga träning de ansågs behöva. Lärarna på avdelningen hade samma roll som Johannes Itten, Paul Klee och Wassily Kandinsky haft på Bauhaus. "Målet var att utveckla studenternas seende och färdigheter och medvetandegöra dem om hur färgers och formers utseende påverkas av komplexa sammanhang," formulerade Gösta Wessel. ${ }^{8}$ Under de två följande åren fördjupades det konstnärliga experimenterandet och sökandet under Färg- och Formperioderna - även det en likhet med vad som skedde på Bauhaus-skolan.

Gösta Wessel var väl förtrogen med både Johannes Ittens och Josef Albers färgteorier och han byggde upp ett färglaboratorium på skolan. Där undersökte han bland annat hur färgpigment och texturer påverkades av bindemedel och hur detta i sin tur påverkade vår upplevelse av färgerna.

Gösta Wessel anknöt i sin artikel i Konstfackhistoriken till Bauhaus: "All utbildning vid Konstfack vilar på konstnärlig grund både av tradition och målmedveten vilja. [---] I likhet med Bauhaus anser vi på Färg och Form att det finns vissa allmänna grundläggande kunskaper i färg och form som är viktiga för en konstnärlig utveckling. [---] Kurserna i fritt måleri på Bauhaus gav upphov till ändlösa diskussioner om konsten roll i förhållande till teknik och design. Dessa diskussioner pågår sedan lång tid tillbaka hos oss och kommer förhoppningsvis att fortsätta även $i$ framtiden. De samlade erfarenheterna från Bauhaus och Bauhaus-traditionens utveckling under 1900-talet är för oss en viktig kunskapskälla."9

Under åren 2006-08 avvecklades institutionen för Färg och Form successivt. Flera konstnärer försvann, gick i pension eller slutade av andra orsaker. Undervisningen blev mer konceptbaserad med ökade krav på teoretiska kunskaper. Konstfack var ju högskola vilket innebar att studenterna skulle ägna sig åt akademisk forskning.

En konstnärlig utbildning är inget slutet kärl. Den är beroende av företeelser i samhället och av impulser och idéer i tiden. Bauhausskolan var inte statisk utan förändrades genom dess egen, inre utveckling och genom skeenden i omvärlden. Så har också Konstfack gjort. Men det är svårt att stoppa studenters egen drivkraft. Materialexperimenten är nu tillbaka.
Bauhauspedagogiken tog ytterligare en väg in i Sverige och det via New Bauhaus i Chicago. Konstnären Adelyne Cross-Eriksson (1905-1979) studerade där på 1940-talet. László Moholy-Nagys övningar i form, textur och struktur samt hans metoder att utveckla sinnesförnimmelserna påverkade henne. Utifrån dessa kunskaper byggde hon under andra världskriget upp en utbildning i Los Angeles för arbetare, husmödrar och andra, övertygad om att alla har en konstnärlig förmåga.

Hon gifte sig med en svensk, sjömannen Per Eriksson. Joseph McCarthys förföljelse av vänsterradikala tvingade dem att lämna Los Angeles och de emigrerade till Sverige 1950. Hon blev senare lärare på Folkuniversitet, dvs. kursverksamheten vid Stockholms universitet. En rad kända kulturpersoner anslöt sig till hennes undervisning. Allt fler blev fascinerade av hennes pedagogik. 1967 startade några av dem tillsammans med Adelyne Cross-Eriksson "Levande Verkstad", som i sin tur har påverkat många konstpedagoger i vårt land. Det visar hur idéer kan vandra vidare, transformeras och ibland ta nya vägar. 


\section{Referenser}

1 Svenska Slöjdföreningens tidskrift hade 1932 döpts om efter den tyska Die Form, som publicerades 1926-1934 av Deutscher Werkbund Den svenska Form-tidskriften utges fortfarande.

2 Form nr 4/1933: 81-86.

3 Form nr 4/1933: 85.

$4 \quad$ Form nr 8/1933, "Tredje riket och

konstindustrin", ej numrerad sida i bakvagnen.

$5 \quad H a n s$ Johan Rabén, (1905-1988), senare

förlagschef och medgrundare av förlaget Rabén \&

Sjögren, 1942, som gav ut barnböcker bl.a. Astrid

Lindgrens Pippi Långström -böcker och som anställde

henne som redaktör på förlaget.

6 Form nr 3/1935: 6-69.

7 Form nr 3/1935: 68.

8 Wessel, "Den konstnärliga grunden".

I Widengren, Gunilla, red. Tanken och handen,

Konstfack 150 år (Stockholm, 1994), 48.

9 Wessel, "Den konstnärliga grunden", 47-51.
Kerstin Wickman (f.1941) är professor emeritus i design- och konsthantverkshistoria, Konstfack. Hon har föreläst om design och konsthantverk sedan slutet av 1960-talet runt om i världen och sedan början av 1970-talet på Konstfack. Hon var under drygt 40 år redaktör på tidskriften Form och har medverkat i ett fyrtiotal böcker om design och konsthantverk.

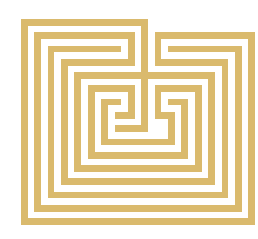

